\title{
Adoption and Scaling-Up of Conservation Agriculture in Tanzania: Case of Arusha and Dodoma Regions
}

\author{
Frederick Cassian Kahimba1, Khamaldin Daud Mutabazi', Siza Donald Tumbo', \\ Kenneth Francis Masuki2 ${ }^{*}$, Winfred Baptist Mbungu ${ }^{1}$ \\ ${ }^{1}$ Soil-Water Management Research Group, Sokoine University of Agriculture, Morogoro, Tanzania \\ ${ }^{2}$ Association for Strengthening Agricultural Research in Eastern and Central Africa (ASARECA), \\ Entebbe, Uganda \\ Email: ${ }^{*}$ kennymasuki@gmail.com
}

Received 28 December 2013; revised 6 February 2014; accepted 21 February 2014

Copyright (C) 2014 by authors and Scientific Research Publishing Inc.

This work is licensed under the Creative Commons Attribution International License (CC BY). http://creativecommons.org/licenses/by/4.0/

\section{Open Access}

\section{Abstract}

A study was conducted to assess the adoption and scaling-up of Conservation Agriculture in Arumeru district, Arusha region, northern Tanzania and Chamwino and Dodoma Urban districts in Dodoma region, Central Tanzania. The study employed structured questionnaire survey and key informant interviews as the main data collection methods. Data analysis was done descriptively to determine factors that influence the adoption. Results showed that farmers in Arusha have highly adopted terraces, minimum tillage and cover cropping whereas their counterparts in Dodoma have highly adopted large planting pits, minimum tillage, and rippers. The intensity of adoption in Arusha is higher for the wealthy compared to the poor while in Dodoma the wealth status was not a factor that influenced adoption of the Conservation Agriculture (CA) technologies. The process of technology adoption should include the use of various participatory methods including farmer field schools, experimental plots, farmer exchange visits, and training of trainers among others. Use of farmer groups, incentives, and support instruments such as Savings and Credit Co-operative Society (SACCOS) or warehouse receipts systems are also important to ensure that farmers realize some acceptable profits from their efforts. Involvement of various stakeholders is also very important including local governments and agricultural change agents at national, regional, district, ward and village levels. Hence, the intention to promote CA technologies should not only look at the economic importance, but also its socio-economic importance to the local people in the area. Their desire to adopt and out-scale a technology should be among the most important investment factors that the government and development partners should consider.

"Corresponding author. 


\section{Keywords}

\section{Social Capital; Diffusion; Water System Innovation; Conservation Agriculture}

\section{Introduction}

Conservation agriculture (CA) as a concept for natural resource saving strives to achieve acceptable profits with high and sustained production levels while concurrently conserving the environment [1]-[3]. It is an approach that advocates the concept of sustainable intensification of production [1]. It is a combination of tested technologies and/or principles in agricultural production and is gaining acceptance as an alternative to both conventional agriculture and organic agriculture as a means of ensuring sustainability [1]. One principle of CA is maintenance of adequate soil cover, especially achieved by leaving crop residues on the soil surface. This is the key to the success of CA systems, and the yield of crops direct-seeded into bare soil is often considerably lower than that of crops sown with conventional tillage practices [4] [5]. CA attempts to maintain a permanent or semi-permanent organic soil cover and promotes the concept of optimizing yields and profits while ensuring provision of local and global environmental benefits and services [6]. A good CA system is required to have at least $30 \%$ of soil surface cover with crop residue at planting for optimum effects of the system [7]. However, at the level of small-scale farmers, CA practice of reduced tillage is constrained with the availability of sufficient crop residues for mulch. This is commonly reported as a problem in sub-Saharan Africa and other many regions [7]-[10]. Delving on this observation, Giller et al. [11], asserted that CA is inappropriate for majority of smallholder farmers because its adoption implies a direct competition for a scarce resource as some crop residues like maize, sorghum or millet straws which are often used for cooking fuel in the scarcity of firewood or other fuels. In more marginal environments, crop productivity is lower and therefore crop residues are scarcer and competition for them greater. Nevertheless, in most cases CA combines modern technologies, with traditional knowledge on soil husbandry. In Tanzania, CA is available and practiced in different forms, the most common ones being: terracing, conservation tillage, pit and trench farming and micro-catchment water harvesting systems. This study was conducted to identify and recommend investment areas in CA with the greatest potential to improve incomes and food security for poor farmers. It specifically focused on determining the extent of adoption and importance of various CA technologies in the case study areas and the estimated spread of the same in Tanzania; assessing the factors that contribute to adoption; investigating the constraints that limit adoption of CA technologies; and recommending steps to be used in promoting adoption and up-scaling of CA technologies in Tanzania.

\section{Methodology}

\subsection{The Study Location}

The study was conducted in Arumeru district in Arusha region, and Chamwino and Dodoma Urban districts in Dodoma region (Figure 1). Arumeru district is located between longitudes $35^{\circ} \mathrm{E}$ and $37^{\circ} \mathrm{E}$ and latitude $3^{\circ} \mathrm{S}$. The district covers an area of $2966 \mathrm{~km}^{2}$, which is $3.5 \%$ of Arusha Region [12]. Despite its proximity to the Equator, Arusha's elevation of $1400 \mathrm{~m}$ amsl on the southern slopes of Mount Meru keeps temperatures relatively low and alleviates humidity. Cool dry air is prevalent for much of the year. The temperature ranges between 13 and 30 degrees Celsius, with an average of around 25 degrees (http://en.wikipedia.org/wiki/Arusha). It has distinct wet and dry seasons with average annual rainfall of $654 \mathrm{~mm}$ (http://www.meoweather.com/).

Dodoma is located at latitude $6^{\circ} \mathrm{S}$ and longitude $35^{\circ} \mathrm{E}$, in the centre of the country. The town is 486 kilometers (302 mi) west of the business city of Dar es Salaam, and 441 kilometers south of the tourist city of Arusha. It covers an area of 2669 square kilometers. Dodoma features a semi-arid climate with relatively warm temperatures throughout the year. The region averages $570 \mathrm{~mm}$ of precipitation per year, the bulk of which occurs during its short wet season between December and March. The remainder of the year comprises dry season.

\subsection{Sampling Techniques and Sample Size}

Five wards whose villages practice CA technologies were purposely chosen in this study. Three wards, Musa 


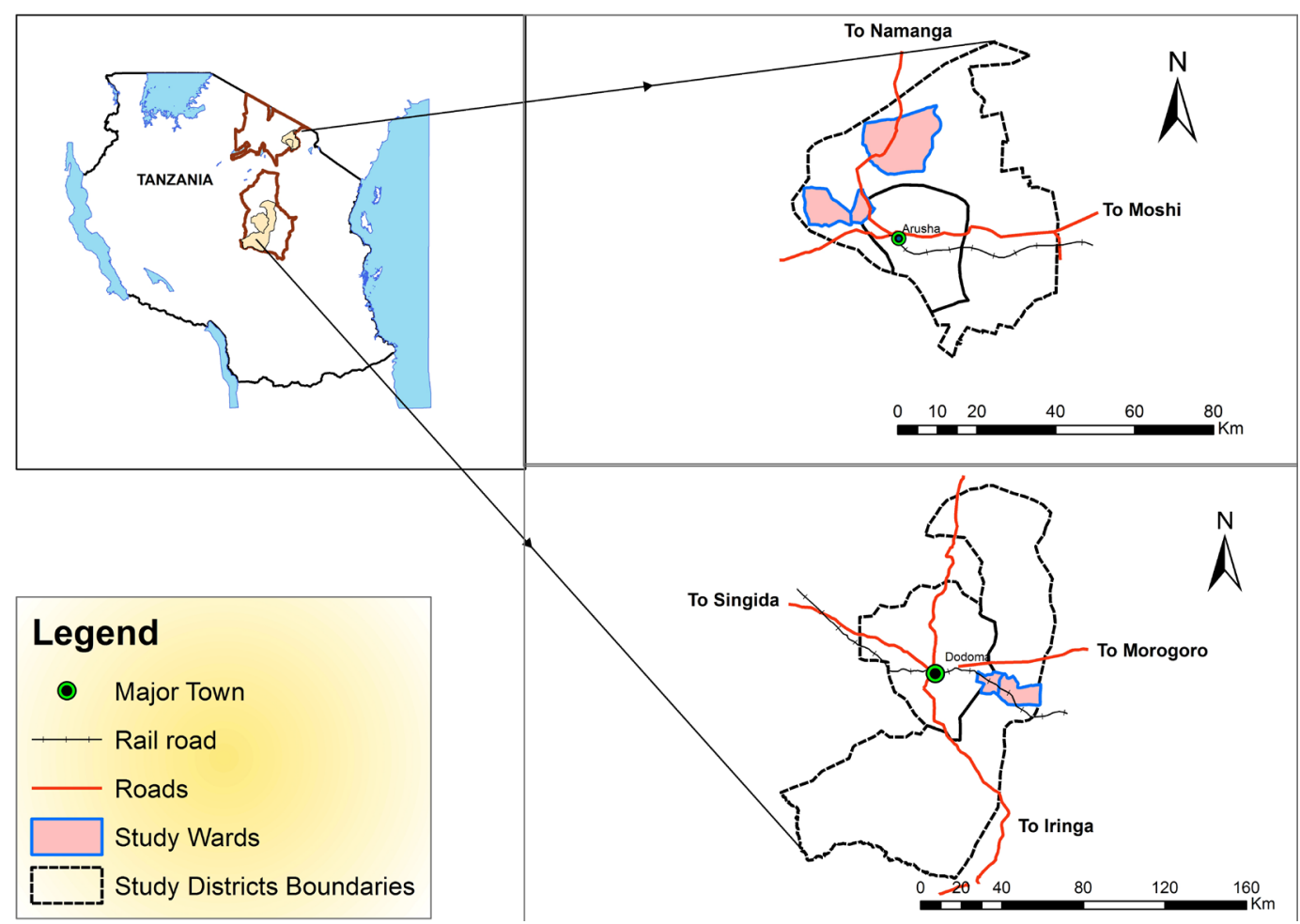

Figure 1. Map of Tanzania showing case study wards and villages in Arusha and Dodoma.

(Likamba village), Olturumet (Ilkuishen and Ekenywa villages) and Oldonyosambu (Oldonyoas village) were chosen in Arumeru district, while Kikombo ward (Kikombo and Chololo villages) was chosen in Dodoma urban district and Msamalo ward (Mnase and Mgunga villages)was chosen in Chamwino district. A total of 200 randomly selected farmers were interviewed from the 8 villages.

\subsection{Data Collection and Analysis}

Structured questionnaire survey and key informant interviews were mainly used for data collection in this study. A structured questionnaire with both open ended and closed question was used to obtain quantitative data from the sampled respondents. The survey was used to collect demographic, crop production and marketing, socioeconomic, livelihood, and food security factors from the sampled respondents. The questionnaire was pre-tested and corrections were made accordingly in one village in Dodoma, and one village in Arusha and adjustments were made before its final administration. A multi-stage sampling technique was employed to get households from different villages. A total of 25 respondents were used from each village to make a total of 100 households from 4 villages for each district.

Key informants interviews were conducted to fill gaps from the questionnaire survey and verify the results. The study involved a wide range of stakeholders from farmers, key village and ward leaders and officials, district leaders and officials, and members of Non-Governmental Organizations (NGOs) that operate in the study areas.

Descriptive analyses were used to determine factors that influence the adoption. The questionnaire survey data was analysed using SPSS statistical package and MS Excel software. Results from the analysis were interpreted and the gaps were also addressed through interviews with key informants.

\section{Results and Discussion}

\subsection{Adoption of Conservation Agriculture and Its Importance to Food Security}

\subsubsection{Roles of CA Technologies in Improving Yields and Food Sufficiency}

Analysis of farmers' responses on losses they would incur if the technologies were not introduced was used to 
assess their perception on the role of a particular technology in sustaining their livelihood. Results from Arusha and Dodoma regions (Figures 2(a) and (b)) imply that the adoption of CA technologies has helped farmers increase yield. Farmers felt that the yields would be affected without CA technologies. The yield losses range from less than $25 \%$ to $100 \%$ with majority of farmers indicating yield losses of about $50 \%$. Farmers indicated that terraces, minimum tillage, large pits and cover cropping have had impacts on crop yields.

Figures 3(a) and (b) show households food self-sufficiency in terms of production and their purchasing power. Results show that majority of respondents in Arusha are capable to producing between $50 \%$ and $75 \%$ of their household requirements and to some extent they can also afford to purchase food in case of some deficits. This group is followed by that capable of producing $75 \%$ to $100 \%$ of their food and with good purchasing power in case of some deficit or crop failure. However, this is contrary to respondents in Dodoma, whom the majority can produce between $25 \%$ and $75 \%$, and majority can afford to some extent to purchase food in case of deficit or crop failure. This information signifies the importance of improving agricultural practices that are geared at increasing production, such as the use of CA technologies, especially in Dodoma where majority are not producing enough and have weak purchasing power.

\subsubsection{Crops grown and Their Yields under Different CA Technologies}

Results of CA technologies with corresponding crops are shown in Tables 1 and 2. In Arusha maize crop was planted across all the CA technologies, due to its importance as both food and cash crop in the region (Table 1). On average about $55 \%$ of all the farms had maize planted, followed by beans $29 \%$, Lablab $6 \%$. The farmers find maize as the crop with a good return to investment compared to others, and would employ the most trusted technology for the production of maize. The high numbers of those who used terraces and minimum tillage and the combination of the two technologies to grow maize confirms that as supported key informants. Beans, though has a good market value, but its harvest has been declining in recent years.

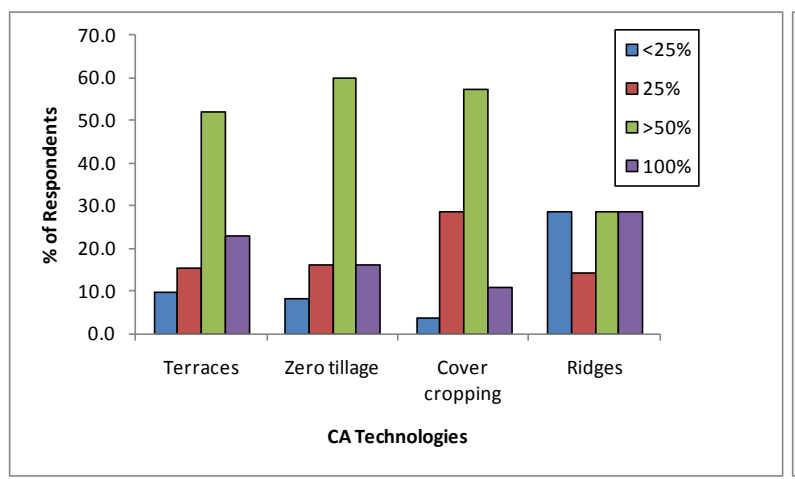

(a)

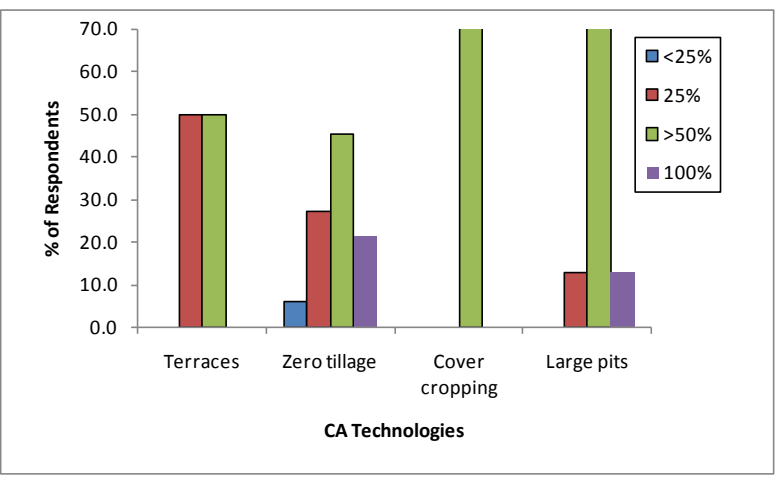

(b)

Figure 2. (a) Loss in yield due to lack of technology in Arusha; (b) Loss in yield due to lack of technology in Dodoma.

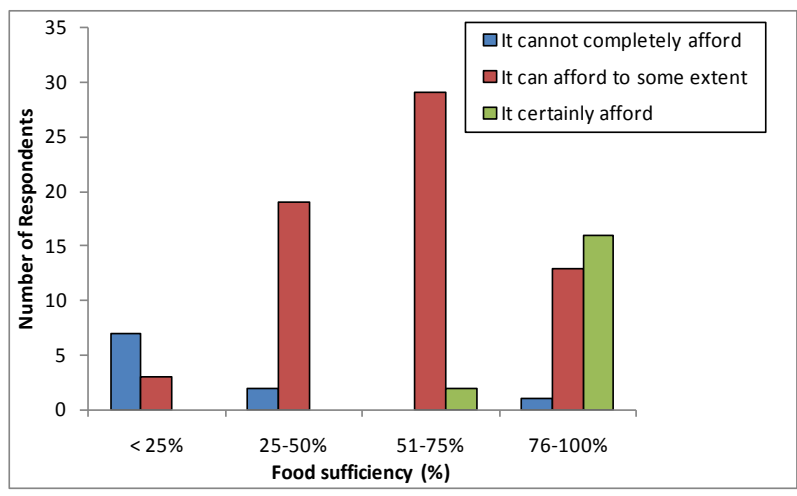

(a)

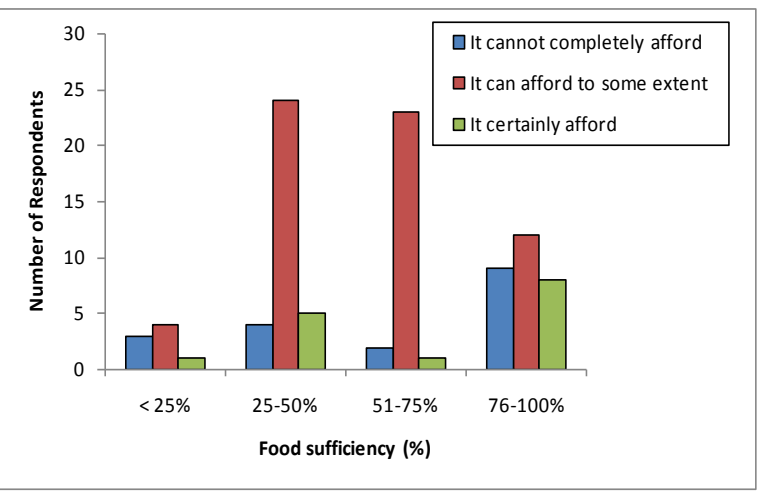

(b)

Figure 3. (a) Household food sufficiency in Arusha; (b) Household food sufficiency in Dodoma. 
Table 1. Proportion of crop types grown under different CA technologies in Arusha.

\begin{tabular}{ccccccc}
\hline CA Technology & Maize & Beans & Vegetables & Lablab & Other & Total \\
\hline Terraces & 60.0 & 32.7 & 1.8 & 1.8 & 3.6 & 100 \\
Minimum tillage & 51.1 & 31.9 & 8.5 & 4.3 & 4.3 & 100 \\
Cover cropping & 47.2 & 33.3 & 0.0 & 2.8 & 16.7 & 100 \\
Ridges & 55.6 & 27.8 & 11.1 & 0.0 & 5.6 & 100 \\
Terraces \& min. tillage & 54.9 & 33.3 & 2.0 & 2.0 & 7.8 & 100 \\
Terraces \& cover crop & 60.0 & 13.3 & 0.0 & 26.7 & 0.0 & 100 \\
Average & $\mathbf{5 4 . 8 .}$ & $\mathbf{2 8 . 7}$ & $\mathbf{3 . 9}$ & $\mathbf{6 . 3}$ & $\mathbf{6 . 3}$ & $\mathbf{1 0 0}$ \\
\hline
\end{tabular}

Table 2. Proportion of crop types grown under different CA technologies in Dodoma.

\begin{tabular}{|c|c|c|c|c|c|c|}
\hline CA Technology & Maize & Sorghum & Groundnuts & Lablab & Others & Total \\
\hline Terraces/Ridges & 15.4 & 46.2 & 15.4 & 23.1 & 0.0 & 100 \\
\hline Minimum tillage & 14.1 & 46.9 & 21.9 & 12.5 & 4.7 & 100 \\
\hline Cover cropping & 27.8 & 11.1 & 44.4 & 11.1 & 5.6 & 100 \\
\hline Large pits & 17.5 & 75.0 & 7.5 & 0.0 & 0.0 & 100 \\
\hline Terraces \& Min. tillage & 15.6 & 23.3 & 36.7 & 18.9 & 5.6 & 100 \\
\hline Terraces \& Cover crop & 9.3 & 25.6 & 30.2 & 34.9 & 0.0 & 100 \\
\hline Average & 16.6 & 38.0 & 26.0 & 16.8 & 2.7 & 100 \\
\hline
\end{tabular}

One farmer Simon Kutingala in Ekenywa village (Kilimapunda CA group) in Arusha during interviews said that:

"Maize has a good market value because it is used by the majority as a food crop, but crop like lablab is mainly bought by traders from the neighbouring country. Beans have a good market value, but the yield has been decreasing in recent years".

In Dodoma region sorghum is the dominant food crop, highly cultivated across all the technologies (38\% of all the crops, Table 2). This crop is a drought tolerant suited to the semi-arid climate of Dodoma (300 - $500 \mathrm{~mm}$ annual rains). For the large pits practice, about $75 \%$ of the crop grown is sorghum. Also, terraces and minimum tillage are employed in the cultivation of sorghum. Cover cropping and a combination of terraces and cover cropping or minimum tillage are mainly employed in groundnuts cultivation.

The yields for different crops in the study area are generally lower, typical of dryland areas in sub-Saharan Africa. This underscores the rationale of promoting CA technologies to improve productivity. On average, terrace performed better (1.3 ton/ha) than other technologies with regard to maize yield (Table 3 ). Other CA technologies under which at least a ton of maize per hectare was realized were large pits and ridges with an average yield range of 1.1 and 1.0 tons/ha respectively. However, at median its only terraces which attained the yield of one ton per hectare. As the median not affected by outliers compared to the mean it stands to be an ideal statistic presenting a typical situation in a particular population.

Ridge technology had much better results on yield of beans. However, only a few farmers practiced ridging in beans production. The yield levels of sorghum, groundnuts, and lablab were typically low across the CA technologies. These four are among the crops promoted in the dryland farming areas of Tanzania including the study sites. Sorghum and groundnuts are common crops grown in Dodoma and across other regions in the semi-arid central part of Tanzania. Lablab is widely grown across the semi-arid northern Tanzania mainly for export to neighbouring country.

The relatively better yield (at median) of sorghum was attained under terracing. However, considering minimum tillage as a control, the typical increment in yield gain (0.2 ton/ha) may not likely cover the costs of terracing in terms of monetary investment and labour. Either, there is no difference in using large planting pits or minimum tillage in sorghum cultivation. However, farmers have indicated that they are likely to loose up to $50 \%$ of the crop if they don't practice CA technology as already indicated in Figure 2. It has been found that in a good year, there is significant difference in yield between conservation tillage and conventional tillage [13]. 
Table 3. Yields of crops under different CA technologies (ton/ha).

\begin{tabular}{|c|c|c|c|c|c|c|c|c|}
\hline \multirow[b]{2}{*}{ Crop } & \multirow[b]{2}{*}{ Statistics } & \multicolumn{7}{|c|}{ CA technology } \\
\hline & & Cover Crop & Terrace & Min. Till & Large pits & Ridges & Terrace + Min. Till & $\begin{array}{c}\text { Terrace + Cover } \\
\text { Crop }\end{array}$ \\
\hline \multirow[t]{4}{*}{ Maize } & $\mathrm{N}$ & 16 & 34 & 24 & 7 & 11 & 42 & 11 \\
\hline & Mean & 0.8 & 1.3 & 0.8 & 1.1 & 1.0 & 0.9 & 1.0 \\
\hline & Std. Dev. & 0.6 & 1.2 & 0.8 & 1.0 & 0.7 & 0.9 & 0.7 \\
\hline & Median & 0.8 & 1.0 & 0.6 & 0.4 & 0.8 & 0.6 & 1.0 \\
\hline \multirow[t]{4}{*}{ Sorghum } & $\mathrm{N}$ & 2 & 2 & 24 & 30 & 3 & 18 & 9 \\
\hline & Mean & 0.3 & 0.5 & 0.5 & 0.4 & 0.3 & 0.5 & 0.6 \\
\hline & Std. Dev. & 0.1 & 0.0 & 0.4 & 0.5 & 0.2 & 0.5 & 0.4 \\
\hline & Median & 0.3 & 0.5 & 0.3 & 0.3 & 0.3 & 0.3 & 0.8 \\
\hline \multirow[t]{4}{*}{ Beans } & $\mathrm{N}$ & 12 & 17 & 8 & - & 5 & 17 & 2 \\
\hline & Mean & 0.4 & 0.2 & 0.8 & - & 1.5 & 0.5 & 0.7 \\
\hline & Std. Dev. & 0.3 & 0.3 & 0.6 & - & 1.3 & 0.4 & 0.3 \\
\hline & Median & 0.3 & 0.1 & 0.6 & - & 1.3 & 0.3 & 0.7 \\
\hline \multirow[t]{4}{*}{ Groundnuts } & $\mathrm{N}$ & 7 & - & 11 & 3 & - & 27 & 8 \\
\hline & Mean & 0.1 & - & 0.3 & 0.1 & - & 0.2 & 0.2 \\
\hline & Std. Dev. & 0.1 & - & 0.2 & 0.1 & - & 0.3 & 0.1 \\
\hline & Median & 0.1 & - & 0.3 & 0.1 & - & 0.1 & 0.2 \\
\hline \multirow[t]{4}{*}{ Lablab } & $\mathrm{N}$ & 2 & - & 7 & - & 2 & 17 & 18 \\
\hline & Mean & 0.9 & - & 0.3 & - & 0.3 & 0.6 & 0.4 \\
\hline & Std. Dev. & 0.9 & - & 0.2 & - & 0.0 & 0.5 & 0.4 \\
\hline & Median & 0.9 & - & 0.3 & - & 0.3 & 0.5 & 0.5 \\
\hline
\end{tabular}

$\mathrm{N}=$ number of observations (valid cases), Min. Till. = Minimum Tillage.

With regard to lablab, it is a cover crop and hence is self-provisioning in terms of benefits of cover crop use. The results indicate that other CA technologies did not result into yields of lablab higher than just growing the crop itself as a cover crop.

\subsubsection{The Extent of Adoption of CA Technologies}

Survey results indicate that the number of farmers adopting different CA techniques varied from place to place depending on biophysical characteristics of the farm areas.

In Arusha region majority of respondents (52.1\%) adopted terraces, followed by almost $23.7 \%$ of the respondents adopting less land disturbing technologies such as zero tillage, ripping, and minimum tillage and about $16.6 \%$ adopting cover crops technology and $6.5 \%$ adopting ridges. However, there was little adoption of such technologies as mulching and jaruba with a combined percentage of 1.1\% (Figure 4(a)). This pattern is likely to happen in Arumeru district due to topographic nature of the study area. Terraces in Arusha are practiced in sloping lands, and in areas where land degradation was high. The key informants confirmed that the intervention of SCAPA program tremendously impacted into their adoption aiming at reducing soil degradation, improving soil fertility through improving water retention, and increasing soil organic matter.

In Dodoma majority of the farmers (29.1\%) have adopted conservation tillage followed by large planting pits (hereafter referred to as large pits and locally known as Chololo ${ }^{1}$ pits) (26.2\%) (Figure 4(b)). The wider practice of conservation tillage is due to the use of ox-drawn rippers, a farming technique that is widely used in the area. Large pits are gaining more popularity due to their ability to conserve soil moisture when the rains are little and the slope is steep for other cultivation methods. Cover crop technique has been adopted by only $8 \%$ of the respondents this is due to that fact that this area practice free grazing mode of livestock keeping where crop

\footnotetext{
${ }^{1} \mathrm{~A}$ Chololo pit is a conservation agriculture technology that holds runoff, and the spaces between the pits act as micro-catchments. It is commonly practiced in Dodoma, central Tanzania [14]. The extra moisture captured in the pits is vital during the initial establishment of crops in this semi-arid area, where the first rains can be erratic.
} 


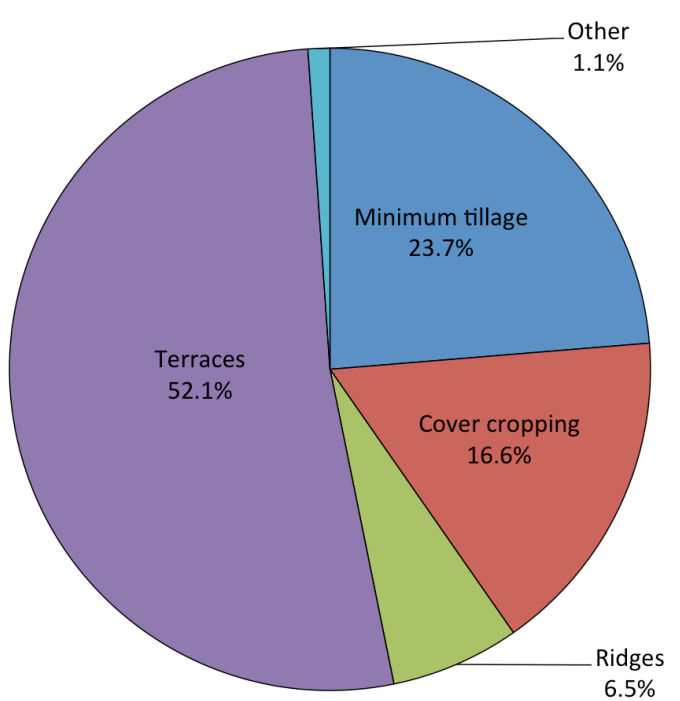

(a)

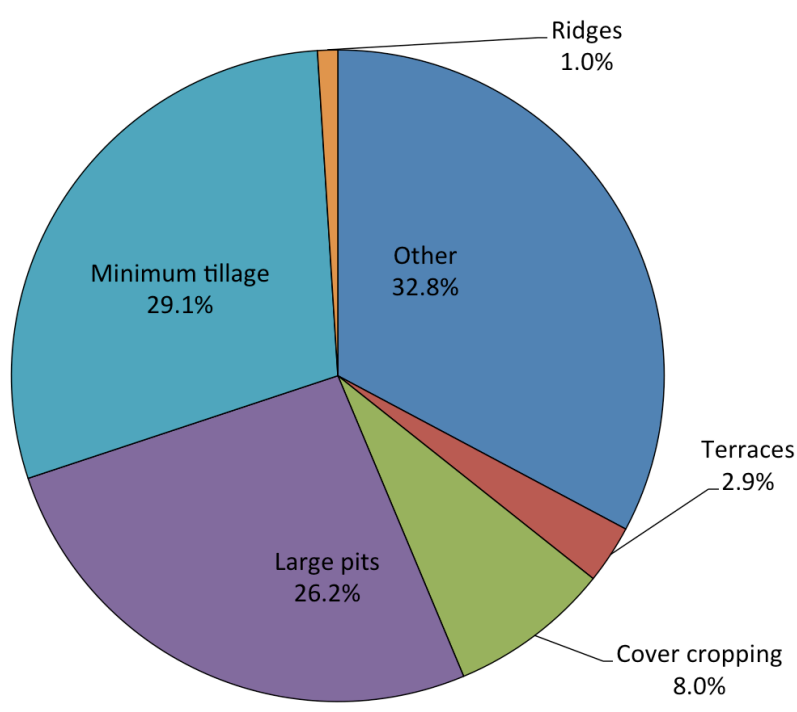

(b)

Figure 4. (a) Adopters of different technologies in Arusha; (b) Adopters of different technologies in Dodoma.

residues serve as animal feeds. This poses a competition between animals and soil cover, the case that has been identified as typical problem of CA system in Sub Saharan Africa (SSA) region [8] [10]. Ridge cultivation $(1.0 \%)$ and terracing $(2.9 \%)$ are not popular technologies in Dodoma region since they cannot easily be made using ox-ploughs, which is a popular cultivating method in the region.

\subsubsection{Types of Farmers Who Adopted Conservation Techniques}

Results of analysis to identify type of farmers who adopted conservation technologies based on wealth status and gender indicate that wealth status influence the decision to adopt conservation technologies. Three wealth groups namely poor, average and wealthier were identified. The indicators used for ranking of wealth status included roofing, floor and wall materials of the main house, and possession of means of transport (motorbike, and bicycle) and cell phone.

In Arusha, majority of farmers that are wealthier have invested on CA technologies in three or more farms (Figure 5(a)). Most of those who have average wealth and the poor have two technologies in their farms. This is contrary to farmers in Dodoma whereby most of them have adopted three technologies regardless of their wealth status (Figure 5(b)). The reason for this pattern is due to the fact that Dodoma being a drier area, farmers had to adopt various technologies for capturing and retaining water.

Results on gender role in household decisions to adopt conservation agriculture technologies are presented in Figures 6(a) and (b). In Arusha, husbands make adoption decision with regard to ridges and terraces ( $>50 \%$ of respondents). For the minimum tillage and cover cropping both husbands and their spouses make the decisions to adopt equally.

In Dodoma over $60 \%$ of the respondents indicated that husbands make the decision to adopt large pits and minimum tillage. However, the decision to adopt cover cropping is made by both husbands and wives equally. This shows that men have an upper edge to decide to adopt technologies that are labour intensive than those, which do not require too much labour such as conservation tillage and cover cropping.

\subsubsection{Estimates of the Spread the CA Technologies in Tanzania}

The spread of CA technologies in the study areas has been facilitated through groups, where farmers form groups through which different stakeholder change agents conduct training. In Arusha, key informants recall that groups were formed in villages and farmers were given training on CA technologies.

"Our group started with 19 members and this is a third year we are practicing CA, many farmers in the village have adopted and the number of those practicing CA has reached more than 50 households in the village, even a primary school within the village has started practicing CA in their farms" said Godwin Sanare a farmer in Ilkuishen village. 


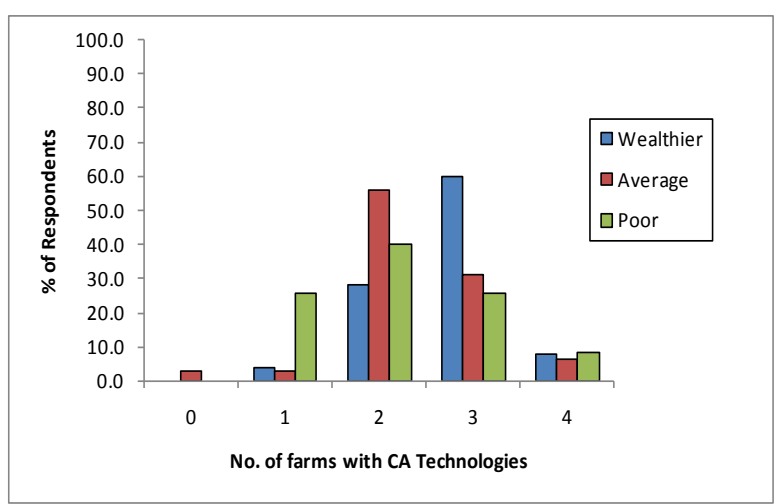

(a)

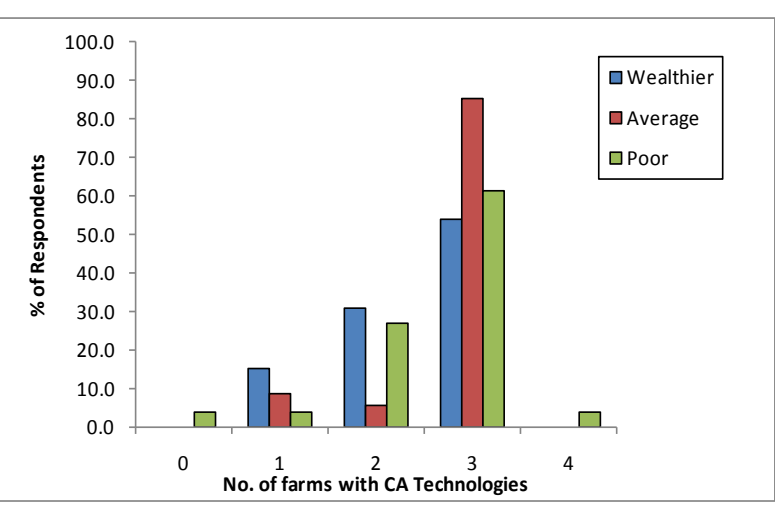

(b)

Figure 5. (a) Farmers adoption of CA technologies based on wealthy status in Arusha; (b) Farmers adoption of CA technologies based on wealthy status in Dodoma.

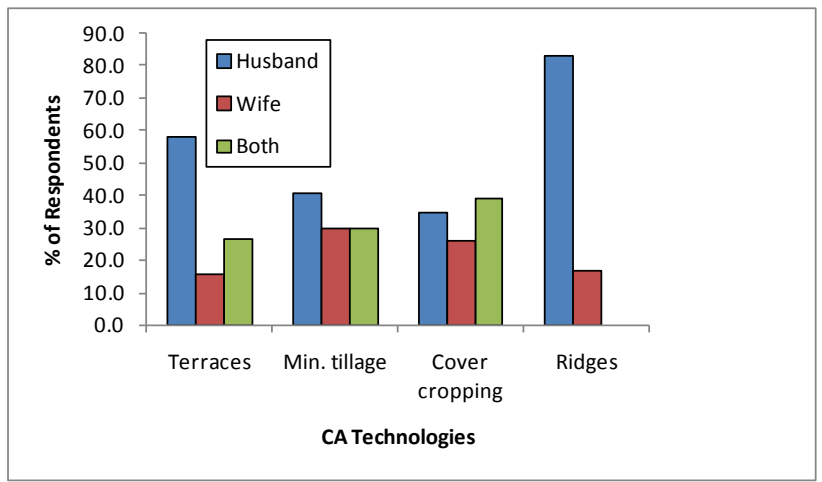

(a)

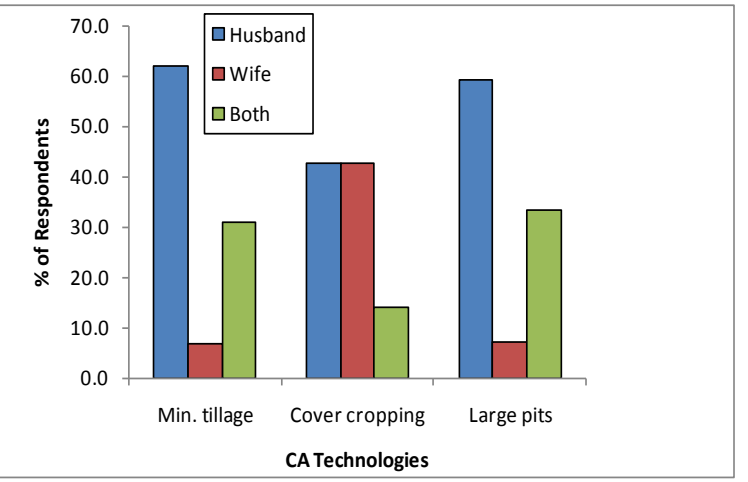

(b)

Figure 6. (a) Gender influence on a decision to adopt CA technologies in Arusha; (b) Gender influence on a decision to adopt CA technologies in Dodoma.

CA technologies started with one group in the Olturumet ward in 2005, but now four CA groups (Merikinoi, Kilimapunda, Tuamke and Olorishi village) have been formed. Another farmer from Ekenywa ward reported that from a group of 26 farmers CA has continued to be adopted by other farmers to more than 80 farmers and many more are adopting. It was also reported that about 300 households in the village from 1200 households in the village have adopted CA technologies. There are also CA groups in other areas such as Nduruma and Enyorata.

Conservation agriculture technologies have been adopted by farmers in places where interventions were promoted. Change agents played a great role in the adoption and widespread of CA technologies. In Arusha, early efforts are credited to Soils Conservation and Agroforestry Project Arusha (SCAPA), which started in the late 1990s. Efforts by NGOs such as Research, Community and Organizational Development Associates (RECODA), Women in Agricultural Development and Environmental Conservation (WADEC), and World Vision in collaboration with Selian Agricultural Research Institute (SARI) through project funded by The Food and Agricultural Organization (FAO) and the district have promoted the adoption of CA in most wards in the district. Interviews with key informants from NGOs and extension agents revealed that CA technologies have spread to 11 out of 21 wards of Arumeru District. The wards are Olturumet, OldonyoSambu, Musa, Namayala, Mlangarini, Maroroni, Kisongo, Nduruma, Manyire, Oljoro, and Oltoroto. Apart from villages and wards in Arumeru district, there have been successes of spreading CA in other districts of Arusha and Manyara regions. Key informant interview revealed that Karatu and Babati Districts were one of the early adopters of CA technologies through the Conservation Agriculture for Sustainable Agriculture and Rural Development (CASARD) project. The farmers, extension agents and NGOs who were interviewed reported that different groups were taken to Karatu and Babati on study tours and field visits to learn about CA. 
The primary focus for Dodoma case study was to investigate the adoption and diffusion of Chololo pits. According to key informant interview, at the moment a farmer group with 25 members is practicing the Chololo pits farming and about 45 - 50 other farmers that are not in the group are also practicing it in the studied villages. The limitation of the technology is that it can only be practiced in heavy soils and sloppy areas. Majority of the village farm-lands are located in flat loamy soils that are not suitable for Chololo pits.

The Chololo pits were invented by inventor farmer from Chololo villagein 1997. Thereafter they were promoted by various NGOs such as Inades Formation Tanzania (IFTz), Lay Volunteer International Association (LVIA), and Muunganowa Vikundivya Wakulima Tanzania [MVIWATA (Union of Farmers groups)]. In Dodoma urban and Chamwino districts the technology has spread in the wards of Handali, Msamalo, Kikombo, Ng'ong'ona, and Makulu. In these wards 60 innovator farmers were trained by IFTz on the Chololo pits. Each of the trained farmers formed their own group of farmers who practiced the technology. The conservation tillage technology (using ox-ploughing) is commonly practiced in Msamalo, Ikoa, Igandu, Handali, Kikombo, and Buigiri wards.

The Chololo pits technology got more publicity when it was involved into competition of best farmer innovations within east Africa region by the UNDP and won a third place. The District Agricultural Development Officer (DALDO) of Chamwino district and Municipal Agricultural Development Officer (MALDO) of Dodoma Urban, have reported that the Chololo pits technology is now being practiced in six districts of Dodoma region namely Dodoma urban, Kongwa, Kondoa, Chamwino, Bahi, and Mpwapwa. The Inades Formation Tanzania officials indicated that the main source of spread is through farmers who visited areas where the technology is being practiced. Also the Inades Formation Tanzania has been proposing adoption of the Chololo pits in the respective districts.

Inades Formation Tanzania officials indicated that semi arid areas of Morogoro, Singida, and Shinyanga, Kilimanjaro, Mwanza, and Manyara regions are potential regions for promotion of Chololo pits as these regions have highlands with steep slope and heavy soils suited for the technology. The CA technologies are currently promoted in other parts of the country like Kilimanjaro and Tanga regions by RECODA; in Morogoro region and in Kilindi district in Tanga region by CARE International; and in the Southern Highlands regions of Mbeya and Njombe by Agricultural Research Institute (ARI) Uyole.

\subsection{Factors Contributing to Adoption and Up-Scaling of CA Technologies in Tanzania}

\subsubsection{Technological and Economic Factors}

Various factors have contributed to the adoption of CA technologies by farmers (Figures 7(a) and (b)). The ability of the CA technology to conserve soil moisture was the main factor for adopting terraces and conservation tillage in Arusha and large pits in Dodoma. Technologies with less labour intensiveness were also favoured in Dodoma region as is the case with minimum tillage and cover cropping. Presence of external incentives such as provision of subsidized farm inputs (e.g. lablab and pigeon pea seeds provided by RECODA and SARI in Arusha), and provision of training on the use of draught animal power at subsidized costs in Dodoma were also contributing factors for farmers to adopt new technologies.

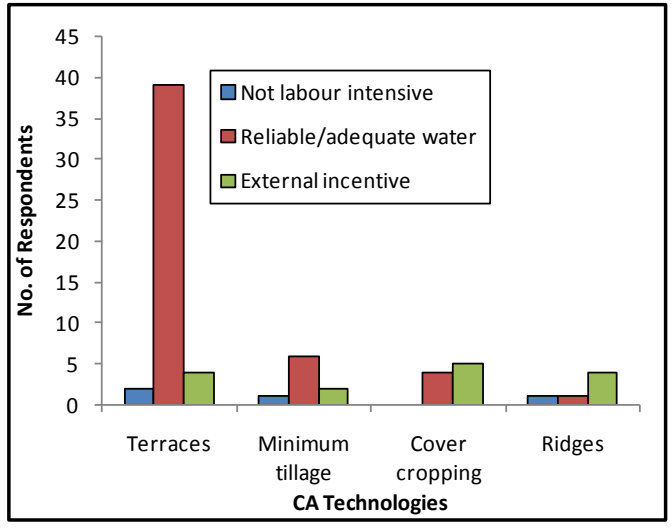

(a)

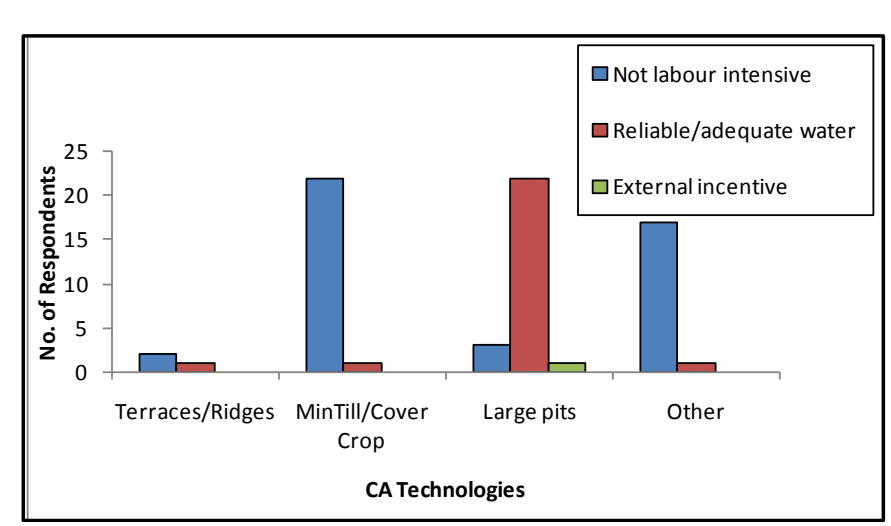

(b)

Figure 7. (a) Reasons for adoption of CA technologies in Arusha; (b) Reasons for adoption of CA technologies in Dodoma. 


\subsubsection{The Roles of Change Agents}

This study hypothesized that the intervention of change agents and the messages that they carry are also a factor that brings wider adoption of technology. Respondents were asked on the number of visits made by the various change agents and the type of messages they passed over. Figure 8 shows the frequency at which change agents were visiting farmers. It is quite clear that extension agents were more in contact with farmers than the other three groups (researchers, NGOs and private sector). The intervention by extension agents is relatively higher in Arusha than Dodoma with exception of one case by the NGOs, which indicates that the "more than twice" visit by NGOs in Dodoma was higher than in Arusha.

The efforts by the government to increase the number of extension workers to the village level are clear as nearly every village has at least one extension officer. The key informants interviews also revealed that apart from the government efforts to increase the number of extension officers, there is a lack of motivation to the staff due to lack of transport to meet the demands and needs of people in the villages. Extension officers themselves expressed the difficult conditions they have to endure to travel from one point to the other and the housing conditions in villages and the lack of training package in CA. Despite having bylaws that prohibit grazing of animals on farms, enforcement of such laws at village level has been hindered by traditions to the detriment of CA adoption efforts.

The advices from the change agents delivered to farmers included agronomic practices, pests and diseases, livestock husbandry, CA technologies and others. In the study area in Arusha, 53.8\% of the advices were on CA technologies while advices on agronomic practices and livestock husbandry were $21.3 \%$ and $17.3 \%$, respectively (Figure 9), indicating higher level of CA technologies promotion compared to other technologies. In Dodoma, the advices higher percent compared to others was on agronomic practices (45.7). Advices on CA technologies came third at $20.0 \%$. This implies that farmers in Arusha were receiving more advices on CA technologies than in Dodoma.

The key informants interviews revealed that the promotion of CA technologies in Arusha started way back 1980's by SCAPA. This project provided training, formation of groups, demonstration of plots and other supports. However, farmers in Mnase Ward in Dodoma, reported that the government was not supportive of their efforts in adopting CA technologies and especially Chololo pits.

\subsubsection{Inputs and Equipment Suppliers}

The inputs and equipment suppliers have helped to bring agricultural inputs and equipment close to the farmers thereby facilitating the adoption and up scaling of the CA technologies. Ward extension officers indicated that in Dodoma region an NGO called LVIA successfully promoted conservation tillage using ox-drawn rippers by conducting training and issuing a set of oxen and ox plough at a subsidized price. Farmers were supposed to pay in three installments after they have sold their harvest. The government also through village extension workers has been distributing improved seeds to farmers at a subsidized price so that majority of the farmers could afford and adopt the used of improved seeds. The farmers also revealed that farmer organizations such as Savings and Credit Co-operative Society (SACCOS) have helped farmers by bringing farm inputs such as fertilizers, pesticides and seeds in store located within villages thereby making them easily accessible to farmers.

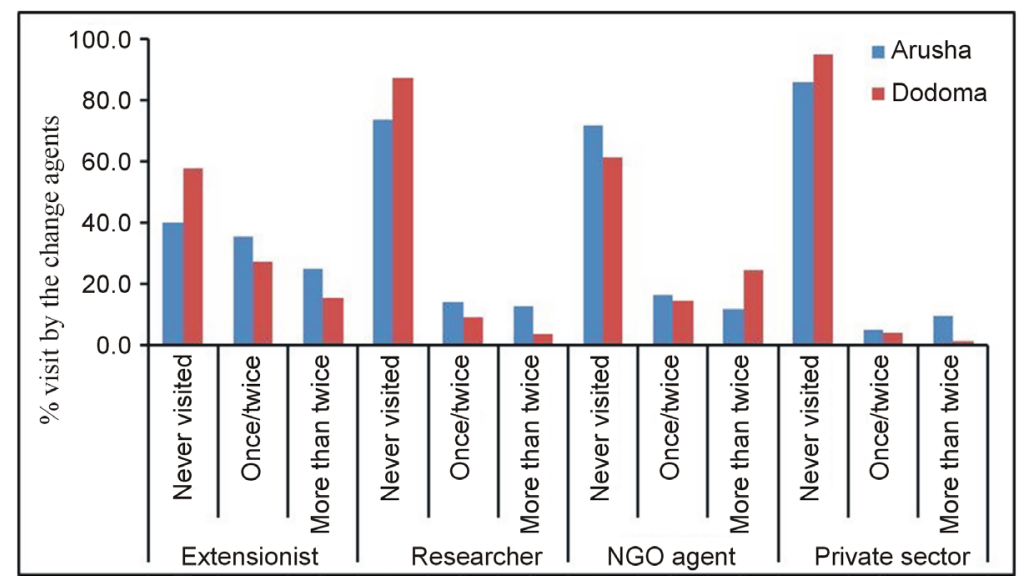

Figure 8. Frequency of contact of farmers by the change agents. 


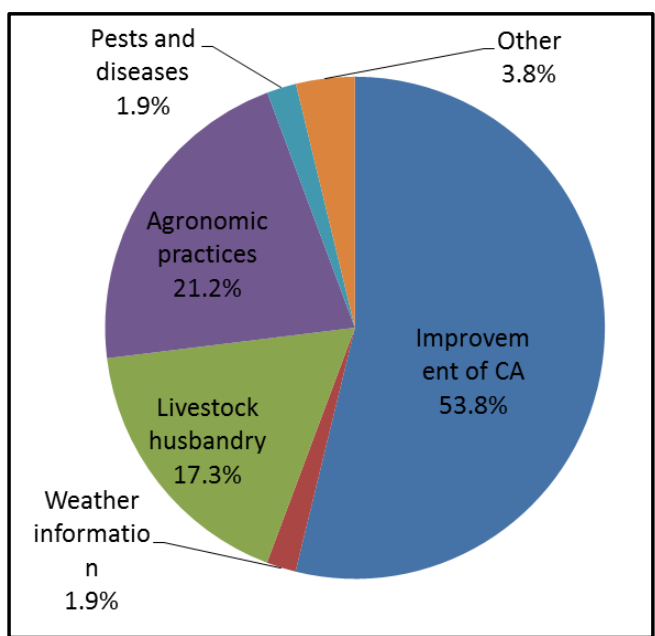

(a)

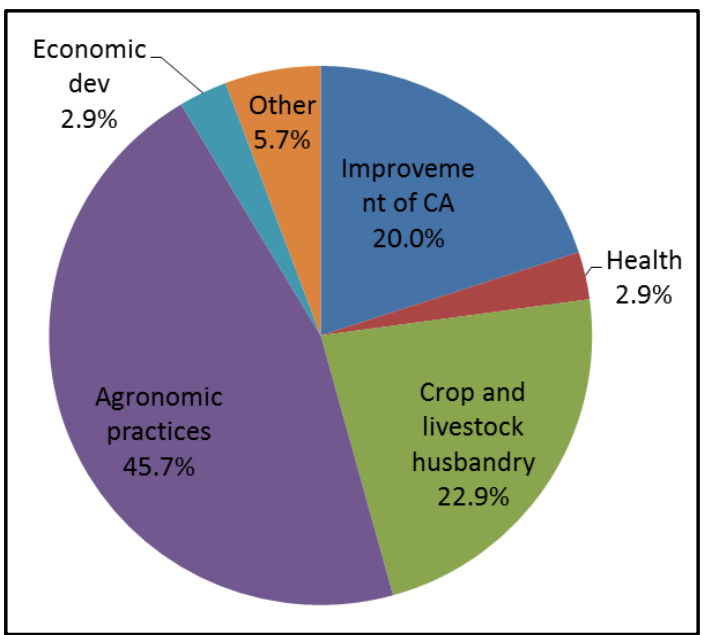

(b)

Figure 9. (a) Advices from change agents in Arusha; (b) Advices from change agents in Dodoma.

\subsubsection{Market Interventions and Communication Infrastructure}

Analysis of places where farmers sell their produce indicated that in Arusha farmers sell mostly dried maize and beans in a nearby township compared to the sales within the village (Figures 10(a) and (b)). On the other hand, sales within the village were the leading market outlets in Dodoma than to neighbouring villages and nearby townships. The leading crops in Dodoma are Sorghum/millet, groundnuts, and Marcia (improved sorghum variety).

Small traders lead the process of buying farm produce in both regions (Figures 11(a) and (b)). Large traders are not common in the villages because most of the farmers are subsistent and they harvest only enough for their household consumption leaving little amount for selling.

With regard to transport and communication infrastructure, the study villages in Arusha do not have year round passable roads with exception of Oldonyo Sambu. However, they are well connected in terms of telecommunication. In Dodoma, the roads are well maintained. There is also a rail service in Kikombo and Msamalo wards. All villages are well connected and served with various mobile telephone networks.

\subsubsection{Policies and Bylaws at National and Local Scale}

Policies and bylaws were mentioned to play a vital role in the adoption and spread of CA technologies. The farmers and change agents noted a number of government policies and local by-laws that influence the adoption of CA. The change agents indicated that the government is keen and supportive on CA.

Formulation, mainstreaming and implementation of proper policy interventions; enforcement of the existing rules and regulations in the areas of land use planning, land tenure, developing smart market and fertilizers subsidies at local, national and sub-regional levels. The National Agricultural Input Voucher Scheme (NAVIS) was identified as one of success ways of implementing agricultural policy through which the government of Tanzania has managed to equip farmers with inputs to support their efforts of alleviating poverty and reducing hunger. The government supports local by-laws that prohibit grazing on farms after harvest, which was limiting CA adoption. At village level an offender of such by-laws are liable to fines. For instance, in Ilkuishen and Ekenywa villages in Oltrumet ward a fine of TZS. 50,000/= was set for a cattle grazing on a field.

The farmers also noted the provision of farm implements to some of the CA groups as one of the efforts to promote CA. The farmers mentioned that the provision of loans by the government in terms of implements to groups and individuals who practice CA was a major boost. A farmer in Ekenywa acknowledged to have received the loan for a direct seeder and has been able to re-pay the loan according to schedule.

\subsection{Constraints That Limit CA Technologies Adoption and Up-Scaling}

\subsubsection{Perception of Limitations for CA Adoption}

Analysis was carried out to investigate why some farmers were not adopting conservation technologies. Labour 


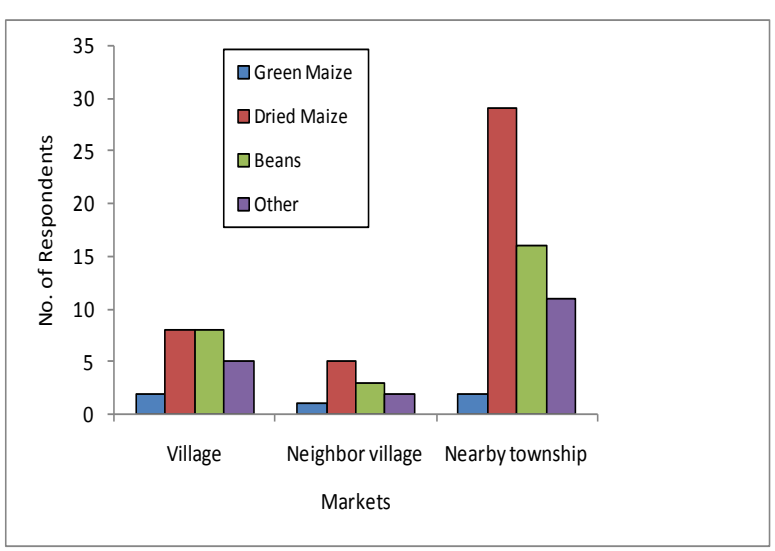

(a)

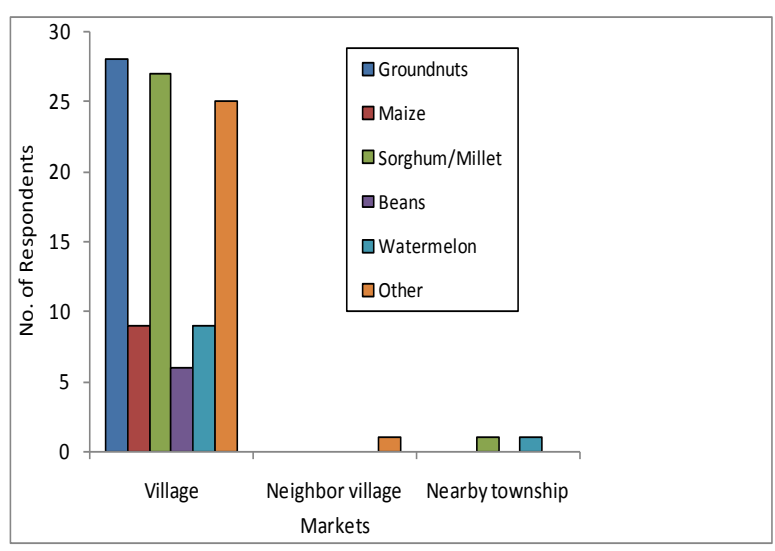

(b)

Figure 10. (a) Markets for farmers to sell their produce in Arusha; (b) Markets for farmers to sell their produce in Dodoma.

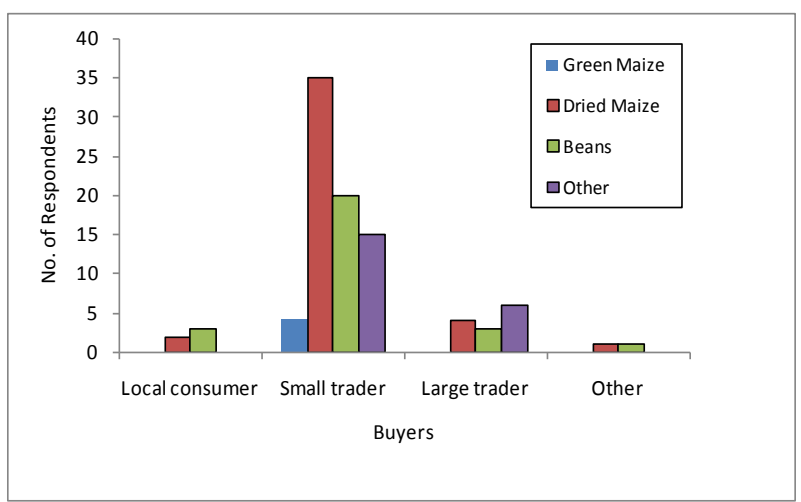

(a)

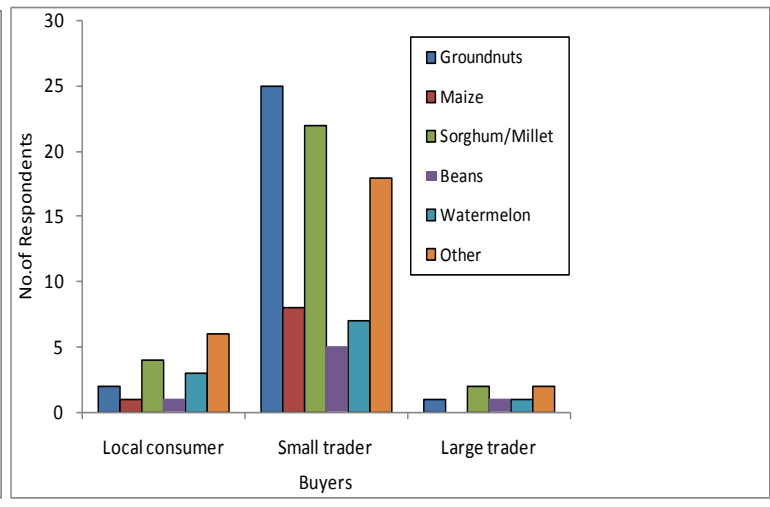

(b)

Figure 11. (a) Buyers of farm produce in Arusha; (b) Buyers of farm produce in Dodoma.

intensiveness, lack of training, and lack of capital to invest in new technologies were the main constraints for farmers not to adopt in Arusha (Figure 12(a)). Lack of training, poverty, and land ownership were the main reasons for farmers not to adopt CA technologies in Dodoma Region (Figure 12(b)). Farmers are hesitant to invest in labour on new technologies such as large pits and terraces on hired farms that they are not sure of continuing to farm in the subsequent season.

Other reasons for non-adoption from both regions were lack of interest, lack of incentives, and time constraints. In addition, availability of farm inputs, costly implements, low returns, and lack of land for implementing the technologies were also reasons mentioned by farmers.

\subsubsection{Technical, Biophysical, and Economic Constrains}

Failure of adoption of the CA technologies was also contributed by some technical, biophysical, and economic constrains. Lack of immediate returns was among the reasons for not adopting as most technologies take more than 2 years for farmers to start realizing results. The key informants also indicated that lack of training to farmers and extension agents was also a major constraint. Interview with farmers indicated that technologies such as the Chololo pits in Dodoma and terraces in Arusha are labour intensive and expensive compared to conventional tillage. Technologies such as Chololo pits are area specific. They are suited to sloping areas with heavy soils. Considering the minimum tillage using ox-drawn equipment, which is a popular technology in Dodoma, most farmers (over 80\%) are subsistent and they do not produce enough to have the financial power to adopt the technologies.

\subsubsection{Legal and Institutional Framework}

Newer technologies originating from farmers (bottom-up) get little support and attention by the system. Local 


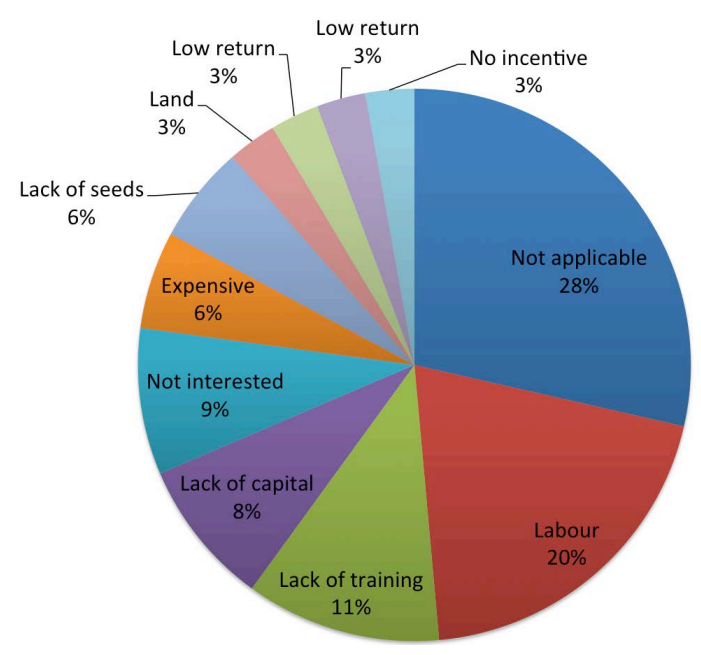

(a)

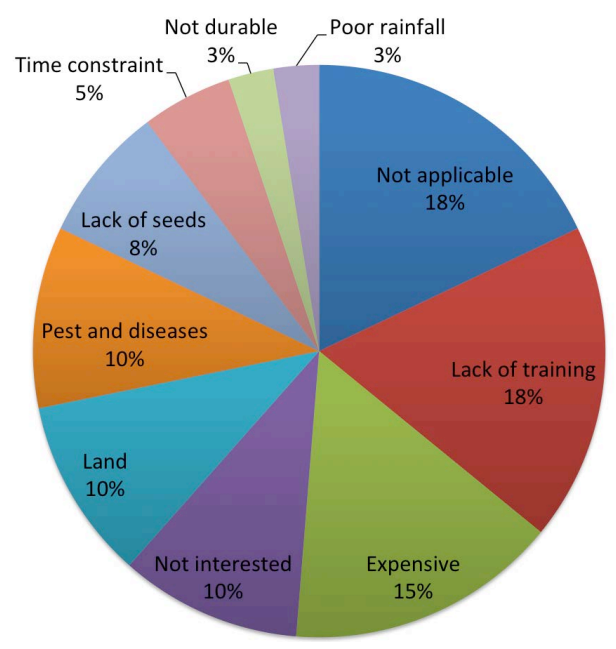

(b)

Figure 12. (a) Limitations for adoption of CA technologies in Arusha; (b) Limitations for adoption of CA technologies in Dodoma.

government continues to support standard and conventional technologies such as bench terracing and minimum tillage using ox-drawn equipment.

Land tenure was also a factor limiting widespread of CA technologies. From the key informants interview many of the younger generations indicated that main reason for failure to invest in CA technologies was lack of ownership of the farms as most of them were hiring from the village elders. Results from the questionnaire survey indicated that $95 \%$ of respondents who adopted CA technologies were owners of the farms. CA technologies involve living crop residues for the next cropping season. However, these residues are sometimes eaten by livestock. In Arusha region there is a bylaw for livestock that destroy crops in the field, which is a fine of TShs 50,000 - - for every cow that is caught grazing on any farm. But the implementation of the fine is hindered by social relationships as most people tend to seek reconciliation to end the matter without paying fines. Finally, extension agents are not well motivated; there is a need for them to be given proper training on CA, transport, and housing facilities.

\subsubsection{Markets and Communication Constraints}

The marketing systems in rural areas within the study villages are not well established and coordinated. Farmers and village leaders revealed that there are no permanent and formal markets within their villages. Despite the presence of farmer groups (SACCOS), there is still poor communication among farmer groups and farmers. As a result the producers lack market information and hence fail to have collective marketing strategies. Every farmer sells same commodities with different inflated prices. On the other hand, presence of number of uncoordinated middlemen is a reason as to why farmers selling their products at very low prices, resulting in low household income. Buyers inflate volume-measuring instruments during purchase of crops from farmers (e.g. $25 \mathrm{~L}$ bucket for a price of $20 \mathrm{~L}$ ), and deflate the volumes during selling back (e.g. $16 \mathrm{~L}$ for a price of $20 \mathrm{~L}$ ). In Dodoma Region, the National Food Reserve Agency (NFRA) used to buy only specialized crop (maize). There is a need for the NFRA to buy more crops such as sorghum, millet and sunflowers, since these are the types of crop grown by majority and are suited to the semi-arid climate characteristics of Dodoma.

\subsubsection{Socio Economic Constrains}

Socio economic issues were among the factors contributing to poor adoption and up-scaling of CA technologies. When different change agents promote the CA technologies in the villages most of the strategies focus on the fewer wealthier farmers (10\%) who can afford to invest on the technologies and buy improved seeds. An example is availability of equipment and tools that are affordable to farmers. This has resulted in majority of the poor farmers failing to afford and hence adopt CA technologies. Subsistence farmers have their alternative means of living such as selling labour, preparing charcoal, and doing small business. They also use livestock as their own 
banks and sell some whenever they get financial problems. Issuance of Government food aids in case of emergency give farmers assurance of government help in case they do not harvest. As a result of this some of the farmers do not see the necessity of adopting CA technologies for conserving soil moisture thereby improving their farm yields.

\subsubsection{Credits, Inputs, and Equipment}

The availability of credits and agricultural inputs and equipment at affordable cost has been a constraint to the adoption of CA technologies in both Arusha and Dodoma regions. In Arusha for example, CA implements such as rippers and no-till seeders initially imported from Brazil, were expensive to most farmers, and only few implements were provided to few groups at the time. Nandra Engineering (a local manufacturer in Moshi), and Centre for Agriculture Mechanization and Rural Technology(CARMATEC) in Arusha started fabricating some of the implements, and selling to farmers at prices cheaper than the Brazil equipment. However, farmers in Arusha indicated that the local made rippers were less durable compared to the Brazilian rippers. Limited number of implements to satisfy their needs in time, especially during the farming season when every farmer needs to work on the farm, was reported to be a major setback to wider adoption of the CA technologies. Apart from few implements in groups, even farmers who are eager to adopt are kept at bay by the unavailability of implements. Farm inputs such as seeds especially those of lablab and pigeon pea were also mentioned to be major constraints limiting adoption as they are not locally available and farmers depend on change agents to provide inputs.

\subsubsection{Limited Promotion and Publicity}

The Chololo pits farming technology in Dodoma was invented in 1997 by a farmer in Chololo village. However, there have been very little efforts to promote and publicise it and thus it did not get a due popularity. While extension workers have been allocated to village and ward levels, they are very few to offer their services adequately to reach out to all the farmers. With regard to publicity of the technologies, especially those invented by farmers, there are very little publications or formal research to advise and popularize the technologies among the research community.

\subsection{Steps for Promoting Adoption and Up-Scaling of CA Technologies in Tanzania}

Key informants identified various steps that are necessary for adoption and up-scaling of CA technologies in Tanzania. Farmers are willing to adopt technologies that have proven to be beneficial in increasing yields, conserving soil moisture, and reducing soil erosion. Also, most farmers are interested in a technology that has a quick and good return to investments.

The first step identified was training on the CA technologies. The advantages obtained due to particular technology should be clearly stipulated to farmers during the training to encourage them to adopt. Apart from training farmers, there is a need to train the change agents who are involved in the promotion of the CA technologies. The second step is formation of groups. The respondents stressed the importance of groups in the adoption of CA technologies. The study revealed that group formation and networking enhanced the adoption and up-scaling processes in Arumeru district.

In general the respondents proposed the steps or actions they would have taken to promote CA technologies if they had their own million dollars as follows:

1) Sensitize extension workers and councilors at District level to gain policy support.

2) Mobilize the community in collaboration with the local government.

3) Establish resource centers (technology incubators) and use them to provide formal training on CA technologies.

4) Establish demonstration plots accompanied with starter packs to assist farmers to easily adopt CA technologies.

5) Promote the trained farmers to be trainer of trainers.

6) Promote research component to come out with improved tools and technologies.

7) Facilitate the trained farmers to establish demo plots on their own farms and later choose to practice the CA technologies they preferred in their farms.

8) Facilitate formation of village committees on various CA technologies. 
9) Promote scaling-out through farmers exchange visits and farmer-to-farmer training.

10) Conduct training on soil water conservation, rainfall characteristics, ecology and biodiversity.

11) Mobilize farmers for collective action in marketing get good prices for their produce e.g. establishment of warehouses, SACCOS or a platform for price negotiation with traders.

\section{Conclusions}

This study has evaluated factors that facilitate or constrain adoption of adoption and up-scaling of CA technologies in central and northern parts of Tanzania. Many studies of this nature have been done under various names including CA, in-situ rainwater harvesting, soil and water conservation measures, and water system innovations, to mention a few. Therefore, the findings and facts have not really changed drastically over time. The need to continue investing in the promotion of CA technologies among others is still there in Tanzania and in Africa South of the Sahara. Most of the CA technologies are area specific, but they bear similar characteristics regardless of locations.

Factors that facilitate or constrain adoption have also not changed with the main factors being technological and economic ones with quick return from investment being another important factor. The scaling-out process is well established in Tanzania and it has proved to be effective in promoting adoption. Important elements in the process include the interactive participatory process such as the use of farmer field schools (FFS), experimentation plots, and farmer exchange visits.

The study showed that sometimes the socio-economic importance of a technology can override its economic significance. For example, sorghum is socioeconomically more important to the people of rural Dodoma even though it might give negative economic returns. Therefore, the intention to promote CA technologies should not only look at the economic importance, but also its socio-economic importance to the local people in the area. Their desire to adopt and out-scale a technology should be among the most important investment factors that the government and development partners should consider.

\section{Acknowledgements}

The authors wish to acknowledge the funding support from the Bill and Melinda Gates Foundation (BMGF) through The Agricultural Water Management (AWM) Solutions project, of which this work was part of it.

\section{References}

[1] Food and Agriculture Organization (2009) Scaling-Up Conservation Agriculture in Africa: Strategy and Approaches. FAO Sub-regional Office for Eastern Africa.

[2] Keraita, B., Drechsel, P. and Konradsen, F. (2010) Up and Down the Sanitation Ladder: Harmonizing the Treatment and Multiple-Barrier Perspectives on Risk Reduction in Wastewater Irrigated Agriculture. Irrigation and Drainage Systems, 24, 23-35. http://dx.doi.org/10.1007/s10795-009-9087-5

[3] Bayala, J., Kalinganire, A., Tchoundjeu, Z., Sinclair, F. and Garrity, D. (2011) Conservation Agriculture with Trees in the West African Sahel-A Review. ICRAF Occasional Paper No. 14. World Agroforestry Centre, Nairobi.

[4] Wall, P. (1999) Experiences with Crop Residue Cover and Direct Seeding in the Bolivian Highlands. Mountain Research and Development, 19, 313-317.

[5] Sayre, K.D., Mezzalama, M. and Martinez, M. (2001) Tillage, Crop Rotation and Crop Residue Management Effects on Maize and Wheat Production for Rainfed Conditions in the Altiplano of Central Mexico. Conservation Agriculture, A Worldwide Challenge. Proceedings of the I World Congress on Conservation Agriculture, Madrid, 1-5 October 2001, 575-585.

[6] Dumanski, J., Peiretti, R., Benetis, J., McGarry, D. and Pieri, C. (2006) The Paradigm of Conservation Tillage. Proceedings of the World Association of Soil and Water Conservation, P1, 58-64.

[7] Fowler, R. and Rockstrom, J. (2001) Conservation Tillage for Sustainable Agriculture-An Agrarian Revolution Gathers Momentum in Africa. Soil \& Tillage Research, 61, 93-107. http://dx.doi.org/10.1016/S0167-1987(01)00181-7

[8] Bationo, A., Kihara, J., Vanlauwe, B., Waswa, B. and Kimetu, J. (2007) Soil Organic Carbon Dynamics, Functions and Management in West African Agro-Ecosystems. Agricultural Systems, 94, 12-25. http://dx.doi.org/10.1016/j.agsy.2005.08.011

[9] Erenstein, O. (2003) Smallholder Conservation Farming in the Tropics and Sub-Tropics: A Guide to the Development and Dissemination of Mulching with Crop Residues and Cover Crops. Agriculture, Ecosystems and Environment, 100, 


\section{7-37. http://dx.doi.org/10.1016/S0167-8809(03)00150-6}

[10] Tursunov, M. (2009) Potential of Conservation Agriculture for Irrigated Cotton and Winter Wheat Production in Khorezm, Aral Sea Basin. Inaugural Dissertation, Institutfür Nutzpflanzenwiss, Und Ressourcenschutz Bodenwissenschaften. University of Bonn.

[11] Giller, K.E., Witter, E., Corbeels, M. and Tittonell, P. (2009) Conservation Agriculture and Smallholder Farming in Africa: The Heretics' view. Field Crops Research, 114, 23-34. http://dx.doi.org/10.1016/j.fcr.2009.06.017

[12] Nyaki, A.S., Lyimo, S.D., Mawenya, L.J., Kalage, K.S. and Antapa, P.L. (1991) Soil and Water Management for Sustainable Smallholder Development: A Field Exercise and Tour Guide in Tanzania. Workshop on Environment and the Poor. WASWC and IIED, Governments of Kenya and Tanzania.

[13] Mkoga, Z.J., Tumbo, S.D., Kihupi, N. and Semoka, J. (2010) Extrapolating Effects of Conservation Tillage on Yield, Soil Moisture and Dry Spell Mitigation Using Simulation Modelling. Physics and Chemistry of the Earth, 35, 686-698. www.elsevier.com/locate/pce http://dx.doi.org/10.1016/j.pce.2010.07.036

[14] Mutunga, K., Critchley, W., Lameck, P., Lwakuba, A. and Mburu, C. (2001) Farmers’ Initiatives in Land Husbandry: Promising Technologies for Drier Areas of East Africa. RELMA Technical Report Series No. 27. UNSO/ESDG/BDP \& RELMA. 